\title{
Drosophila DOCK Family Protein Zizimin Involves in Pigment Cell Differentiation in Pupal Retinae
}

\author{
Fumito Ozasa ${ }^{\dagger}$ Kazushige Morishita ${ }^{\dagger}$, Dang Ngoc Anh Suong, Seiji Miyata, Hideki Yoshida, and \\ Masamitsu Yamaguchi* \\ Department of Applied Biology, The Center for Advanced Insect Research, Kyoto Institute of Technology, \\ Matsugasaki, Sakyo-ku, Kyoto 606-8585, Japan
}

\begin{abstract}
The dedicator of cytokinesis (DOCK) family proteins are known as one of guanine nucleotide exchange factors (GEFs), that contribute to cellular signaling processes by activating small G proteins. Although mammalian Zizimin is known to be a GEF for Cdc42 of Rho family small GTPase, its role in vivo is not well understood. Here we studied in vivo function of Drosophila Zizimin (Ziz). Knockdown of Ziz in eye imaginal discs induced the rough eye phenotype accompanied with fusion of ommatidia, loss of bristles and loss of pigments. Immunostaining analyses revealed that Ziz mainly localizes in the secondary pigment cells (SPCs) and tertiary pigment cells (TPCs) in pupal retinae. Ziz-knockdown induced SPC- and TPC-like cells with aberrant morphology in the pupal retina. Delta $(\mathrm{Dl})$, a downstream target of EGFR signaling is known to regulate pigment cell differentiation. Loss-of-function mutation of $D l$ suppressed the rough eye phenotype and the defect in differentiation of SPCs and TPCs in Ziz-knockdown flies. Moreover, Ziz-knockdown increased Dl expression level especially in SPCs and TPCs. In addition, mutations of rhomboid-1 and roughoid that are activators of EGFR signaling pathway also suppressed both the rough eye phenotype and the defect in differentiation of SPCs and TPCs in $Z i z$-knockdown flies. Activation of EGFR signaling in Ziz-knockdown flies were further confirmed by immunostaining with anti-diphospho ERK IgG. These results indicate that Ziz negatively regulates the DI expression in SPCs and TPCs to control differentiation of pigment cells and this regulation is mediated by EGFR signaling pathway.
\end{abstract}

Key words: Zizimin, DOCK, EGFR signaling pathway, pigment cell, Drosophila

\section{Introduction}

The Rho family of small GTPases including Rho, Rac and Cdc42 work as small molecular switches and are involved in the regulation of many cellular processes such as cytoskeletal organization, cytokinesis, cell morphogenesis, cell migration and development (Dumontier et al., 2000; Jaffe and Hall, 2005; Mondal et al., 2007; Kölsch et al., 2008; Para et al., 2009). Activities of these small GTPases are regulated by guanine nucleotide exchange factors (GEFs), GTPase-activating proteins (GAPs) and guanine nucleotide dissociation inhibitors (GDIs) (Jaffe and Hall, 2005). DOCK (dedicator of cytokinesis) family proteins belong to GEF proteins and activate small GTPases (Meller et al.,

\footnotetext{
$\dagger$ These authors contributed equally to this work.

*To whom correspondence should be addressed: Masamitsu Yamaguchi, Department of Applied Biology, Kyoto Institute of Technology, Sakyo-ku, Kyoto 606-8585, Japan.

Tel: +81-75-724-7781

E-mail: myamaguc@kit.ac.jp
}

2005; Côté and Vuori, 2007).

DOCK family proteins are conserved among a wide variety species such as nematode, fruit fly and human. In mammals, 11 DOCK-family proteins, DOCK1 (DOCK180) to DOCK11, have been identified. DOCK-family proteins can be further classified into four subfamilies, DOCK-A, DOCK-B, DOCK-C and DOCK-D, according to their protein structures. DOCK1, DOCK2 and DOCK5 belong to DOCK-A; DOCK3 and DOCK4 belong to DOCK-B; DOCK6, DOCK7 and DOCK8 belong to DOCK-C; DOCK9, DOCK10 and DOCK11 belong to DOCK-D. Each subfamily has DOCK Homology Region (DHR) 1 and DHR2 domain. DHR1 domain determines the subcellular localization and DHR2 domain catalyzes GEF activity (Meller et al., 2005). DOCK-A and DOCK-B have Srchomology-3 (SH3) domain in the N-terminal regions, which binds to proline-rich region of the ELMO protein (Brugnera et al., 2002). DOCK-D contains a Pleckstrin Homology $(\mathrm{PH})$ domain involved in membrane localization through phospholipid binding (Zheng et al., 1996). 
DOCK1 localizes in the cytoplasm and binds to ELMO. Responding to the cell signals, the DOCK1/ELMO complex associates to the plasma membrane that allows DOCK1 to get contact with its substrate Rac to exchange the nucleotide of the Rac. In mammals, the DOCK1/ELMO complex is necessary for Rac-mediated cell migration, dendritic spine morphogenesis, phagocytosis and myoblast fusion (deBakker et al., 2004; Laurin et al., 2008; Vasyutina et al., 2009; Kim et al., 2011). Other DOCK-A and DOCK-B proteins also exchange the nucleotide of Rac. However, other studies reported that DOCK4, one of the DOCK-B subfamily proteins, can also exchange the nucleotide of Rap (Yajnik et al., 2003). Previous studies revealed that DOCK1, DOCK4 and DOCK5 are expressed in the nervous system (Miyamoto and Yamauchi, 2010). Other studies have shown that DOCK2 is expressed specifically in hematopoietic cells, but DOCK3 is expressed in brain and spinal cord (Reif and Cyster, 2002; Namekata et al., 2004; Chen et al., 2009).

DOCK-C proteins, also designated as Zizimin-related proteins (Zir), play a role in central and peripheral nervous systems. Zir1 (DOCK6) regulates growth of axons and regeneration of sensory neurons (Miyamoto et al., 2007). Zir2 (DOCK7) is involved in microtubule localization, neuronal axon formation and cell migration (Watabe-Uchida et al., 2006). Zir3 (DOCK8) plays a role in lamellipodia formation, cell migration, cell proliferation and adhesion (Engelhardt et al., 2009; Harada et al., 2012). DOCK-D proteins also called as Zizimin-family (Ziz) have been mainly characterized in mammalian cultured cells. Ziz1 (DOCK9) is reported to be important for filopodia formation and dendrite development (Meller et al., 2002, 2005; Kuramoto et al., 2009). Ziz2 (DOCK11) is responsible for filopodia formation and cell migration (Meller et al., 2002; Sakabe et al., 2012). Ziz3 (DOCK10) is involved in amoeboid invasion (Gadea et al., 2008).

Current studies have also shown that DOCK family proteins are related to several neurodegenerative and neuropsychiatric diseases. DOCK-A is implicated in Alzheimer disease and Parkinson's disease (Cimino et al., 2009; Pankratz et al., 2011). DOCK-B is also implicated in Alzheimer disease (Tachi et al., 2012). DOCK-D (Ziz) is related to bipolar disorder and autism (Detera-Wadleigh et al., 2007; Pertz et al., 2008). However, pathogenic mechanism of these diseases in relation to DOCK-family proteins is not fully understood yet.

In Drosophila, four DOCK family proteins have been identified. Myoblast city (Mbc), Sponge (Spg), Ziziminrelated (Zir) and Zizimin (Ziz) belong to DOCK-A, DOCK-B, DOCK-C and DOCK-D subfamilies, respectively. Mbc has a similar function to DOCK1 and is involved in myoblast fusion in Drosophila (Erickson et al., 1997; Bour et al., 2000). Recent studies have revealed that Spg positively regulates ERK signaling pathway during the differentiation of R7 photoreceptor cells (Eguchi et al.,
2013). Duolink in situ PLA method using specific antibodies to Spg and Rap1 revealed that this positive regulation is mediated by interaction of Spg with Rap1. Spg also plays a critical role in ASP development and tracheal cell viability that is mediated by the ERK signaling pathway (Morishita et al., 2017). In contrast, during thorax development, Spg positively regulates JNK pathway and this regulation is mediated by its association with Rac1 (Morishita et al., 2014). Spg also regulates development of the central nervous system (CNS) with ELMO during embryogenesis (Biersmith et al., 2011). Other studies reported that in Zir mutants, lamellocytes, a haemocyte subtype in Drosophila fail to encapsulate the parasites and macrophage-like plasmatocytes exhibit a reduced ability in phogocytosis of the infected bacteria (Sampson et al., 2012). In addition, Zir genetically interacts with $R a c 2$ and $C d c 42$ during these encapsulation and phagocytosis. Therefore, Zir appears to be necessary to activate Rac2 and Cdc42 during the cellular immune response in Drosophila (Sampson et al., 2012). Although studies in mammalian cultured cells and Dictyostelium revealed a role of Ziz in cell migration, development, cytokinesis and growth (Pakes et al., 2013), in vivo function of Ziz is still not fully understood.

In the present study, we found that knockdown of $\mathrm{Ziz}$ in eye imaginal discs induces severe loss of red pigment phenotype in adult compound eyes. Drosophila has three types of pigment cells: primary pigment cells, PPCs; secondary pigment cells, SPCs; tertiary pigment cells, TPCs. Differentiation of these pigment cells is well known to be mediated by Delta (Dl) and Shaven (Sv), a homologue of mammalian Pax2 (Malartre, 2016). Detailed genetic and cytological studies have revealed that Ziz negatively regulates the $D l$ expression in PPCs in pupal retinae to control pigment cell differentiation and this regulation is mediated by epidermal grows factor receptor (EGFR) signaling pathway.

\section{Materials and Methods}

\section{Oligonucleotides}

To construct the plasmids pGEX6P-1-Ziz $z_{1815-2252}$, the following oligonucleotides were synthesized.

$Z i z_{1815}$ BamHI: 5'-GCGGGATGGATCCAGATTGCTGGAACTG $Z_{2 i z_{225}}$ XhoI: 5'-AGCTAGTGAGCTCGTCGTCCAGCAACTC

\section{Plasmid construction}

To generate pGEX6-1-Ziz $z_{1815-2252}$, the Ziz cDNA fragment was amplified from total RNA extracted from third-instar larvae by using Prime Script ${ }^{\mathrm{TM}}$ Hi-Fidenlity RT-PCR kit (Takara) with primer oligonucleotides $Z i z_{1815}$ BamHI and $Z i z_{2252}$ XhoI. The PCR products were digested with BamHI and $\mathrm{XhoI}$ and inserted between these sites of the pGEX6P-1 vector (GE Healthcare). 


\section{Purification of the GST-tag fusion proteins and production of anti-Ziz IgG}

GST-Ziz $_{1815-2252}$ fusion proteins were expressed in E. coli BL21 (DE3). Lysates of cells were prepared by adding $20 \mu \mathrm{l}$ of 10 $\mathrm{mg} / \mathrm{ml}$ Lysozyme in $20 \mathrm{mM}$ Tris- $\mathrm{HCl}(\mathrm{pH} 8.0)$ and supernatants and pellets were separated by centrifugation at $12,000 \times \mathrm{g}$ for 30 $\min$ at $4^{\circ} \mathrm{C}$. GST-Ziz ${ }_{1815-2252}$ fusion protein in the supernatants was purified and GST-tag was finally removed by using PreScission protease (GE Healthcare). The purified $\mathrm{Ziz}_{1815-2252}$ protein was used to elicit polyclonal antibody production in guinea pig. The anti-Ziz IgG was purified by using Protein A Mag Sepharose ${ }^{\mathrm{TM}}$ Xtra (GE Healthcare) according to the manufacture's instruction.

\section{Fly stocks}

Fly stocks were normally cultured at $25^{\circ} \mathrm{C}$ on standard food unless it is indicated as $28^{\circ} \mathrm{C}$. Canton S fly was used as a wildtype strain. Enhancer trap lines carrying the lacZ makers B38 (inserted in klingon) (Butler et al., 1997), P82 (inserted in deadpan) (Kramer et al., 1995) and AE127 (inserted in seven-up) (Mlodzik et al., 1990) were obtained from Y Hiromi. These lines express the $\beta$-galactosidase marker in photoreceptor cells R7, $\mathrm{R} 3 / \mathrm{R} 4 / \mathrm{R} 7, \mathrm{R} 1 / \mathrm{R} 3 / \mathrm{R} 4 / \mathrm{R} 6$, respectively. The fly line carrying UASZizIR, Shaven (Sv)-lacZ, UAS-GFPIR, UAS-Rac1 N17, were obtained from Bloomington Drosophila Stock Center. The GMRGAL4 and other stocks used in this study were obtained from the Kyoto Drosophila Genetic Resource Center, Bloomington Drosophila Stock Center or Vienna Drosophila Resource Center.

\section{Scanning electron microscopy}

Adult flies were anesthetized, mounted on stages and inspected with a scanning electron microscope in high vacuum mode (VE-7800, Keyence Inc.). The eye phenotype of at least five adult male flies (3 to 5 days after eclosion) from each line was examined in each experiment and the experiments were repeated three times. No significant variation in eye phenotype was observed among these five individuals.

\section{Immunostaining}

For immunohistochemistry, larval eye imaginal disc and pupal retinae were dissected in PBS, then fixed in $4 \%$ paraformaldehyde/PBS for $20 \mathrm{~min}$ and $30 \mathrm{~min}$ at $25^{\circ} \mathrm{C}$, respectively. After washing with PBS containing $0.3 \%$ Triton X-100, the samples were blocked with $10 \%$ normal goat serum with PBS containing $0.3 \%$ Triton $\mathrm{X}-100$ for $20 \mathrm{~min}$ and $30 \mathrm{~min}$ at $25^{\circ} \mathrm{C}$, respectively. After blocking, primary antibodies were added and incubated for $16 \mathrm{~h}$ at $4{ }^{\circ} \mathrm{C}$. The following antibodies were used; mouse monoclonal anti-lacZ IgG (diluted at 1:500, DSHB), antiDlg aintibody (1:500, DSHB), guinea pig anti-Ziz IgG $(1: 2,000)$, anti-Delta (Dl) IgG (1:10, DSHB), anti-diphospho ERK (dpERK) IgG (Sigma) (1:100 dilution) and anti-active Caspase 3 IgG (1:500, BD). After washing with PBS containing $0.3 \%$ Triton
X-100, samples were incubated with secondary antibodies labeled with either Alexa 488 or Alexa 594 (1:400, Invitrogen) for $3 \mathrm{~h}$ at $25^{\circ} \mathrm{C}$. Alexa 594-conjugated phalloidin (200 units/ml, Invitrogen) was used for the detection of F-actin. After washing with PBS containing $0.3 \%$ Triton X-100 followed by washing with PBS, samples were mounted in Vectashield (Vector Lab) and inspected with an Olympus FV-10i laser confocal microscope.

\section{Western immunoblotting}

Protein extracts were prepared from the wild type adult heads. After dissection in PBS, the tissues were boiled for $2 \mathrm{~min}$ in the extraction buffer (100 mM Tris- $\mathrm{HCl} \mathrm{pH} 7.4,0.1 \mathrm{mM}$ PMSF and $10 \%$ Protease Inhibitor Cocktail Complete Mini (Roche). Sample buffer $(62.5 \mathrm{mM}$ Tris-HCl pH 6.8, 2.5\% SDS, 0.02\% Bromophenol Blue, $5 \% \beta$-mercaptoethanol, 10\% glycerol, Protease Inhibitor Cocktail (Nacalai tesque)) was then added and homogenized. After boiled for $5 \mathrm{~min}$, insoluble fractions were taken away from solution by centrifugation at $12,000 \times \mathrm{g}$ for $10 \mathrm{~min}$ at $4{ }^{\circ} \mathrm{C}$. The proteins were applied to a SDS-polyacrylamide gel containing $8 \%$ acrylamide and transferred to polyvinylidenedifluoride membrane (Bio-Rad) in transfer buffer (25 mM Trizma base, $192 \mathrm{mM}$ glycine and 5\% methanol). After blotting, membranes were blocked in 5\% skim milk, diluted with PBS containing $0.05 \%(\mathrm{v} / \mathrm{v})$ Triton $\mathrm{X}-100$. The blotted membrane was then incubated with anti-Ziz IgG at 1:2000 dilutions at $4^{\circ} \mathrm{C}$ for $16 \mathrm{~h}$. After washing with PBS containing $0.05 \%(\mathrm{v} / \mathrm{v})$ Triton X-100, the bound antibodies were detected with the peroxidase-conjugated anti-guinea pig IgG and ECL system (GE Healthcare). The images were analyzed with an image analyzer, AE-9300H Ez-Capture MG (ATTO).

\section{Results}

\section{Ziz is required for Drosophila eye development}

In order to clarify the function of Ziz in Drosophila, we examined the effects of knockdown of $\mathrm{Ziz}$ in several tissues using a combination of the GAL4-UAS system and RNA interference method (Table I). We used three independent transgenic flies carrying UAS-ZizIR targeted to two different regions of $\mathrm{Ziz}$ mRNA. Expression of double strand RNA (dsRNA) of Ziz with en-GAL4 driver that expresses

Table I. Summary of PHENOtypes InduCED By KNOCKDOWn OF ZIZ With SEVERAL GAL4 DRIVER LINES

\begin{tabular}{lccc}
\hline \multirow{2}{*}{ GAL4 line } & \multicolumn{3}{c}{ Phenotypes with UAS-Ziz-IR } \\
\cline { 2 - 4 } & $5343-5869$ & $5344-5715$ & $6430-6556$ \\
\hline GMR & rough eye & rough eye & rough eye \\
eyeless & ND & ND & embryonic lethal \\
engrailed & ND & embryonic lethal & embryonic lethal \\
elav & ND & ND & ND \\
pannier & ND & ND & ND \\
\hline
\end{tabular}

ND: No detectable phenotype 

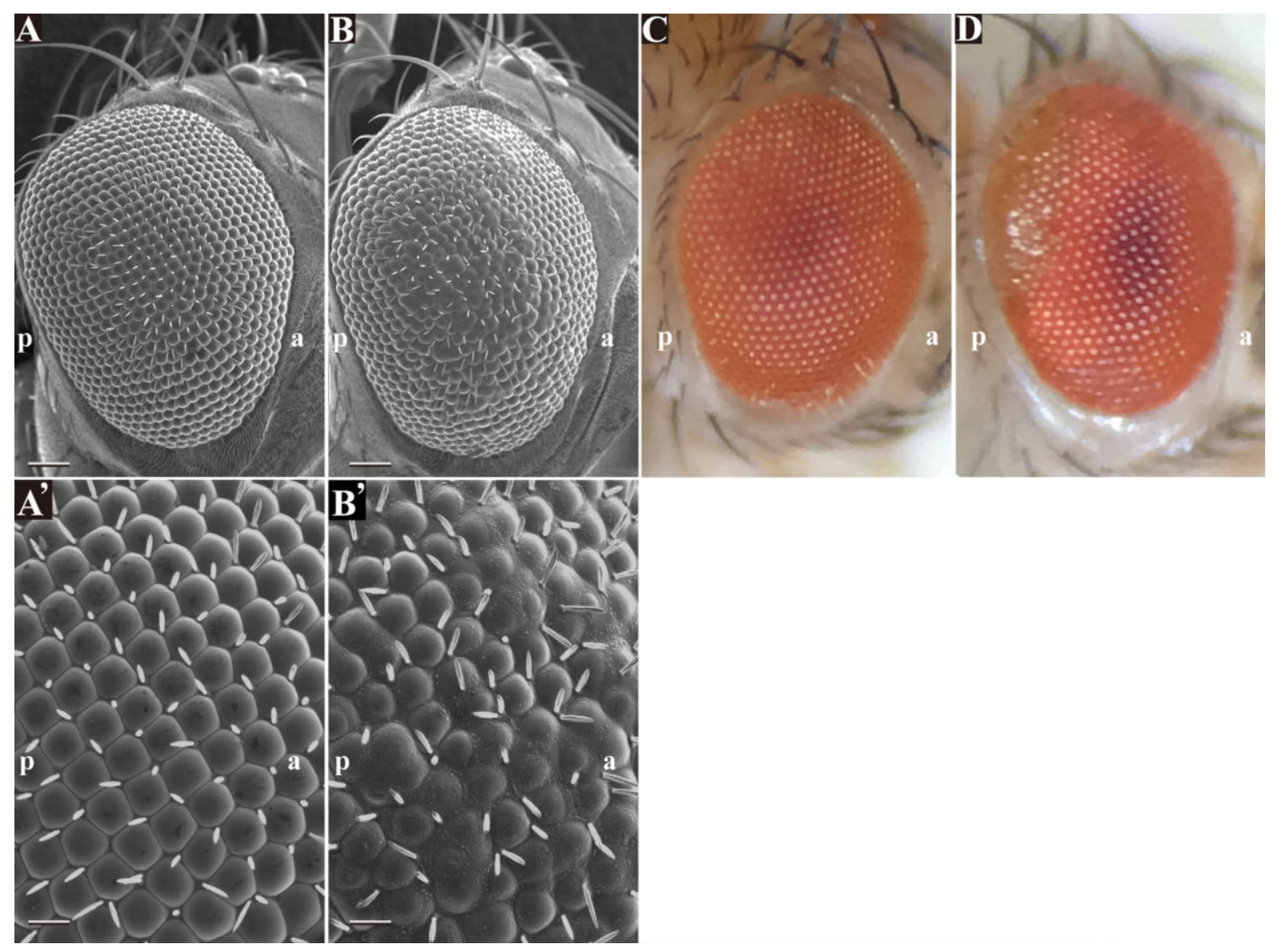

Fig. 1. Ziz-knockdown in eye imaginal disc induced rough eye and loss-of-pigment phenotype in posterior region of the adult compound eye. (A, A', B, B') scanning electron micrographs of adult compound eyes. (C, D) Stereoscopic micrographs of adult compound eyes. (A, A', C) GMR-GAL4/Y; +; UAS$G F P-I R /+$. (B, B', D) GMR-GAL4/Y; UAS-Ziz-IR ${ }_{6430-6556} /+;+$. The flies were developed at $28^{\circ} \mathrm{C}$. The bars indicate $50 \mu \mathrm{m}(\mathrm{A}, \mathrm{B})$ and $14.2 \mu \mathrm{m}\left(\mathrm{A}^{\prime}, \mathrm{B}^{\prime}\right)$, respectively. a, anterior; $\mathrm{p}$, posterior.

GAL4 in posterior compartments induced embryonic lethality, suggesting that $\mathrm{Ziz}$ is an essential gene and required for embryogenesis. Knockdown of Ziz by using GMR-GAL4 driver, in which Ziz dsRNA is expressed in posterior region of the morphogenetic furrow (MF) in eye imaginal discs, induced fusion of ommatidia and loss of bristles, a rough eye phenotype (Fig. 1B, B') in compared to the control (Fig. 1A, A'). There are two kinds of pigments, drosopterin and ommochrome in the adult compound eye. Drosopterin or both pigments may be decreased in the adult compound eye (Fig. 1C, D). Each independent transgenic fly strain showed the same phenotype, suggesting that the rough eye phenotype and loss-of-pigment phenotype are not due to a possible insertion effect of the inverted repeats.

To clarify function of Ziz in vivo, we firstly examined the differentiation of photoreceptor cells in Ziz-knockdown flies (Fig. 2). The Ziz-knockdown flies were crossed with the enhancer trap lines P82, B38 and AE127. The enhancer trap lines P82 and B38 specifically express $\beta$-galactosidase
(lacZ) in photoreceptor cells R3/R4/R7 and R7, respectively (Kramer et al., 1995; Butler et al., 1997). The AE127 line specifically expresses lacZ in photoreceptor cells R1/R3/R4/R6 (Mlodzik et al., 1990). Immunostaining of the eye imaginal discs with anti-lacZ $\operatorname{IgG}$ revealed that $\mathrm{R} 3 / \mathrm{R} 4 / \mathrm{R} 7$ signals were detected in the P82 control flies and knockdown of Ziz exerted no effect on the R3/R4/R7 signals (Fig. 2C, D). There is also no difference of photoreceptor signals in AE127 and B38 between control flies and the knockdown flies (Fig. 2A, B, E, F). These results indicate that Ziz-knockdown exerts no detectable defects in the differentiation of photoreceptor cells.

Since relatively high expression of $\mathrm{Ziz}$ at pupal stage is noted in FlyBase (http://flybase.org/reports/ FBgn0260486.html), the affinity-purified anti-Ziz IgG was used for immunostaining with pupal retinae of Canton S. Drosophila has three types of pigment cells: primary pigment cells, PPCs; secondary pigment cells, SPCs; tertiary pigment cells, TPCs (Wolff and Ready, 1993). In the pupal 

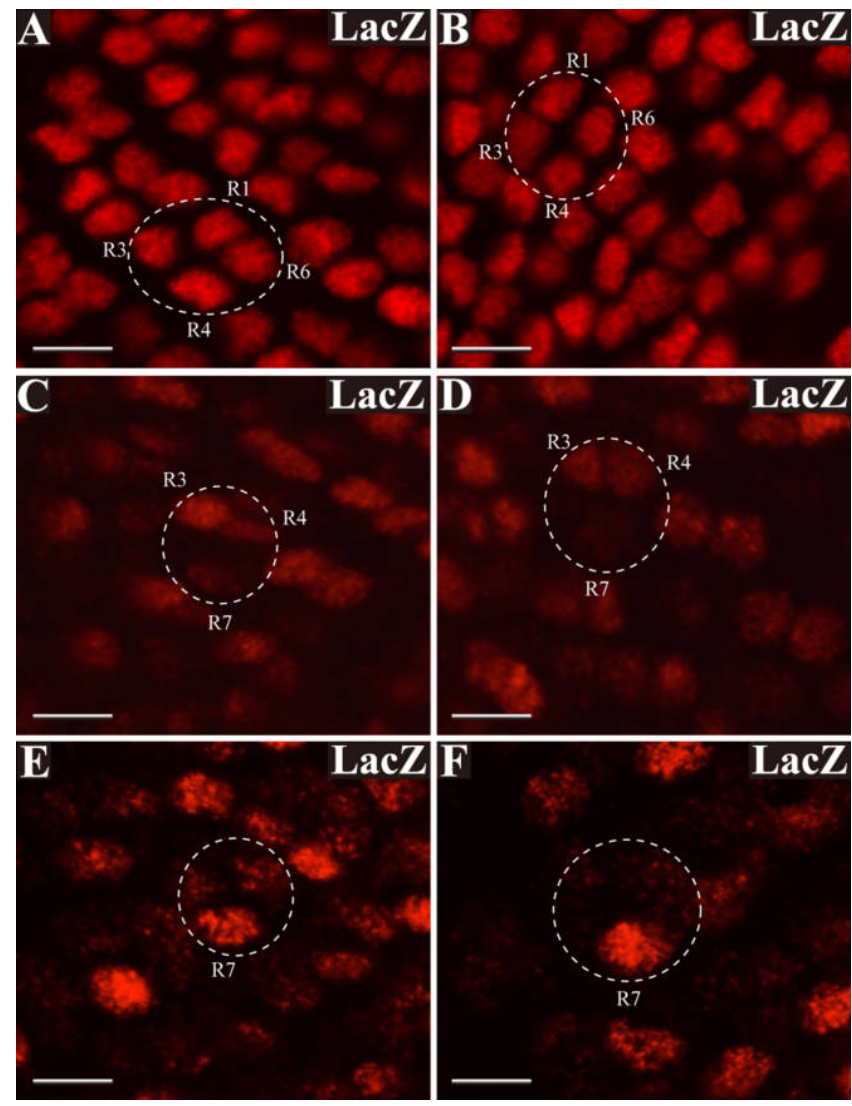

Fig. 2. Photoreceptor cells in Ziz knockdown flies. Immunostaining of eye imaginal discs with anti-lacZ IgG (red). (A) GMR-GAL4/Y; +; UASGFP-IR/AE127 (B) GMR-GAL4/Y; UAS-Ziz-IR ${ }_{6430-6556} /+; A E 127 /+$. (C) GMR-GAL4/Y; +; UAS-GFP-IR/P82. (D) GMR-GAL4/Y; UAS-Ziz-IR 6430 ${ }_{6556} /+$; P82/+. (E) GMR-GAL4/Y; +; UAS-GFP-IR/B38. (F) GMR GAL4/Y; UAS-Ziz-IR $6430-6556 /+; B 38 /+$. The enhancer trap lines, AE127 (A, B), P82 (C, D) and B38 (E, F), expressed lacZ in R1/R3/R4/R6, $\mathrm{R} 3 / \mathrm{R} 4 / \mathrm{R} 7$ and $\mathrm{R} 7$, respectively. The flies were developed at $28^{\circ} \mathrm{C}$. The bars indicate $5 \mu \mathrm{m}$. An ommatidium is enclosed in each panel.

retinae of Canton $\mathrm{S}$ at $42 \mathrm{~h}$ after puparium formation (APF), cone cells and the pigment cells in each ommatidium were marked with the anti-Dlg aintibody (Fig. 3B, E, $\mathrm{H})$. The Ziz signals were mainly detected in SPCs and TPCs as bright dots (Fig. 3A-C). In the images with deeper focal planes, no Ziz signal was detected in photoreceptor cells (Fig. 3D-I). These data indicate that the Ziz was specifically expressed in pigment cells in the pupal retina.

In the pupal retinae of GMR-GAL4>GFPIR flies at $42 \mathrm{~h}$ after puparium formation (APF), cone cells and the pigment cells in each ommatidium were marked with the antiDlg aintibody (Fig. 4B and E). The Ziz signals were again detected in SPCs and TPCs as bright dots (Fig. 4A-C). However, in the Ziz-knockdown flies, the signals of $\mathrm{Ziz}$ in the SPCs and TPCs were strikingly decreased, confirming the efficient knockdown of $Z i z$ in GMR-GAL4> ZizIR flies (Fig. 4D-F). The quantified data indicate that Ziz signal intensities were decreased to $42 \%$ in the Ziz-knockdown flies (Fig. 4G). These data indicate that the Ziz was efficiently knocked down in the pupal retina and the antibody is specific to $\mathrm{Ziz}$ protein. The specificity of anti-Ziz IgG was further confirmed by Western immunoblot analysis with the extracts from wild type adult fly heads. The Western blot detected a single $260 \mathrm{kDa}$ band that is nearly identical to the calculated value of $257.2 \mathrm{kDa}$ (Fig. $4 \mathrm{H}$ ).

\section{Ziz-knockdown increases morphologically aberrant pigment cells in pupal retinae}

Ziz-knockdown in eye imaginal disc not only induced rough eye phenotype but also decreased the pigments (Fig. 1A-D). Therefore, Ziz may have important roles in pigment cell differentiation. In Ziz-knockdown flies, apparently SPC- and TPC-like cells with larger size were increased in pupal retina (Fig. 4E) in compared with the control flies (Fig. 4B). These results suggest that Ziz plays an important role in pigment cell differentiation in pupal retina. The defects in morphology of SPC- and TPC-like cells in Zizknockdown flies are severer in posterior region than in anterior region (Fig. 4I-K), corresponding to severer lossof-pigment phenotype in posterior region of the adult compound eyes (Fig. 1D).

\section{Ziz negatively regulates the $\mathrm{Dl}$ expression during pigment cell development}

As described above, Ziz-knockdown induced the decrease of pigments in ommatidia and likely inhibited proper differentiation of pigment cells. Moreover, Ziz is preferentially expressed in SPCs and TPCs (Fig. 3A). In eye development, both spitz (spi) and Delta $(D l)$ play an important role in differentiation of cells including photoreceptor cells, cone cells and pigment cells (Roignant and Treisman, 2009). Cone cells express high level of $\mathrm{Dl}$, a ligand of Notch receptor and Shaven $(S v)$, both of which are required to differentiate PPCs (Carthew, 2007; Malartre, 2016). Then, PPCs produce the SPCs and TPCs mediated by cell contacts and/or apoptosis. Since transcription of both $D l$ and $S v$ is regulated by EGFR pathway (Roignant and Treisman, 2009), we next examined the genetic interaction between $\mathrm{Ziz}$ and genes related to EGFR signaling pathway.

Drosophila rhomboid-1 (rho) and roughoid (ru) cooperate to activate EGFR pathway in eye development (Wasserman et al., 2000). We therefore crossed Zizknockdown flies with loss-of-function mutants of rho and $r u$ (Fig. 5). Effective suppression of the rough eye phenotype by these mutations was observed (Fig. 5B, C and 5B', $\mathrm{C}^{\prime}$ ) in compared to the Ziz knockdown alone (Fig. 5A, $\mathrm{A}^{\prime}$ ). These data suggest that Ziz negatively regulates the rho and $r u$ activities during pigment cell development. Furthermore, the morphologically aberrant SPCs and TPCs induced by Ziz-knockdown appeared to be partially suppressed by half 

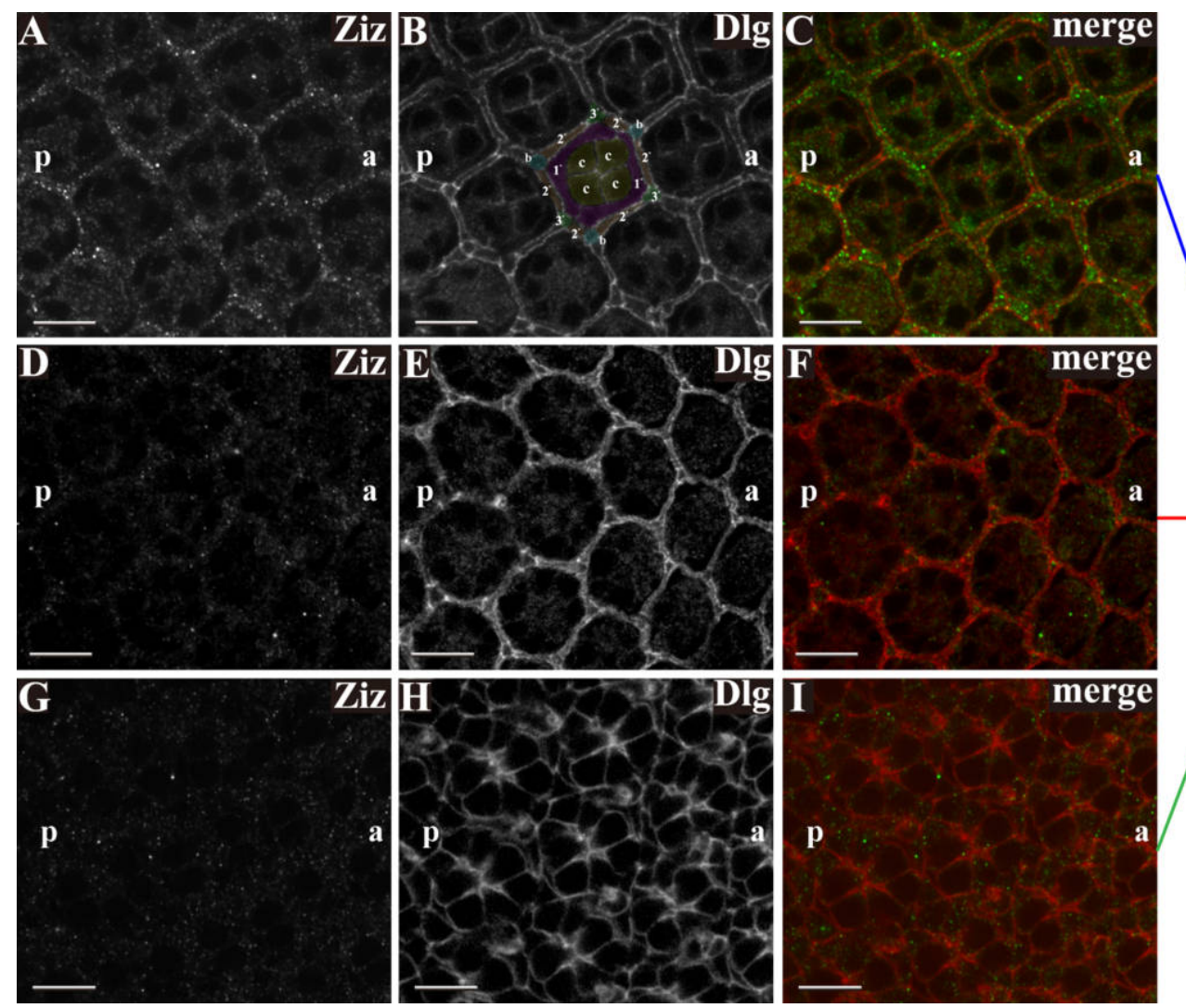

Fig. 3. Expression pattern of Ziz in pupal retinae of Canton S. (A, D, G) Immnunostaining of 42h APF pupal retina with anti-Ziz IgG. (B, E, H) Cell membranes were immunostained with anti-Dlg antibody. (C, F, I) Merged image of Ziz signals (green) in A, D, G and Dlg signals (red) in B, E, H, respectively. (J) Side view of an ommatidium. Focal planes for A, B, C, those of D, E, F and those of G, H, I are indicated with blue, red and green lines, respectively. The photoreceptor cells (R), PPCs $\left(1^{\circ}\right), \operatorname{SPCs}\left(2^{\circ}\right), \operatorname{TPCs}\left(3^{\circ}\right)$, bristle (b) and cone cells (c) are marked. The bars indicate $10 \mu \mathrm{m}$. a, anterior; p, posterior.

dose reduction of the rho gene in pupal retinae (Fig. 5J) in compared to the Ziz-knockdown alone (Fig. 5I). Zizknockdown flies show defects in the positioning of anterior/posterior cone cells and pigment cells when they were reared at $28^{\circ} \mathrm{C}$ (Fig. 5I) compared to the control (Fig. 5H). These defects in the cell positioning were also effectively suppressed. The Ziz-knockdown flies were also crossed with loss-of-function mutants of several other genes that are related to the EGFR pathway such as Ras $85 D, D l$, spi and egfr (Fig. 5D, E, F, G) (Wasserman et al., 2000). In Zizknockdown flies, loss-of-function mutation of $D l$ strongly suppressed the rough eye phenotype (Fig. 5E, E'), the defect in differentiation of the SPCs/TPCs and the positioning of anterior/posterior cone cells and pigment cells (Fig. $5 \mathrm{~K})$. We also observed that Ras $85 \mathrm{D}$ mutation could rescue the rough eye phenotype induced by Ziz-knockdown (Fig. $\left.5 \mathrm{D}, \mathrm{D}^{\prime}\right)$. However, half-reduction of spi or egfr gene dose exerted no apparent effect on the rough eye phenotype (Fig. $\left.5 \mathrm{~F}, \mathrm{~F}^{\prime}, \mathrm{G}, \mathrm{G}^{\prime}\right)$, suggesting that these two components may not be rate-limiting in EGFR signaling pathway. We also performed immunostaining analyses with anti-dpERK IgG to monitor activation of EGFR signaling pathway. In the SPCs/TPCs-like cells of Ziz-knockdown flies, the dpERK signals were increased (Fig. 6D-F) in compared to the control (Fig. 6A-C). Taken together, these results suggest that Ziz negatively regulates EGFR signaling pathway.

Since transcription of both $D l$ and $S v$ is regulated by EGFR pathway (Roignant and Treisman, 2009), we next examined the expression of $D l$ and $S v$ in $Z i z$-knockdown retinae. Immunostaining of pupal retinae with anti-Dl $\operatorname{IgG}$ revealed that Dl expression is strongly enhanced in the morphologically aberrant SPCs- and TPCs-like cells together with cone cells by Ziz-knockdown (Fig. 7D-F) in compared to the control (Fig. 7A-C). Expression of $S v$ was also examined by monitoring $S v$-lacZ expression. The immunostaining data with anti-lacZ $\operatorname{IgG}$ revealed that $S v$ expression is not affected by Ziz-knockdown (Fig. 8D-F) in compared to the control (Fig. 8A-C). Taken together, these results indicate that $\mathrm{Ziz}$ negatively regulates $\mathrm{Dl}$ expression in vivo, and this regulation is likely mediated by EGFR signaling pathway. 

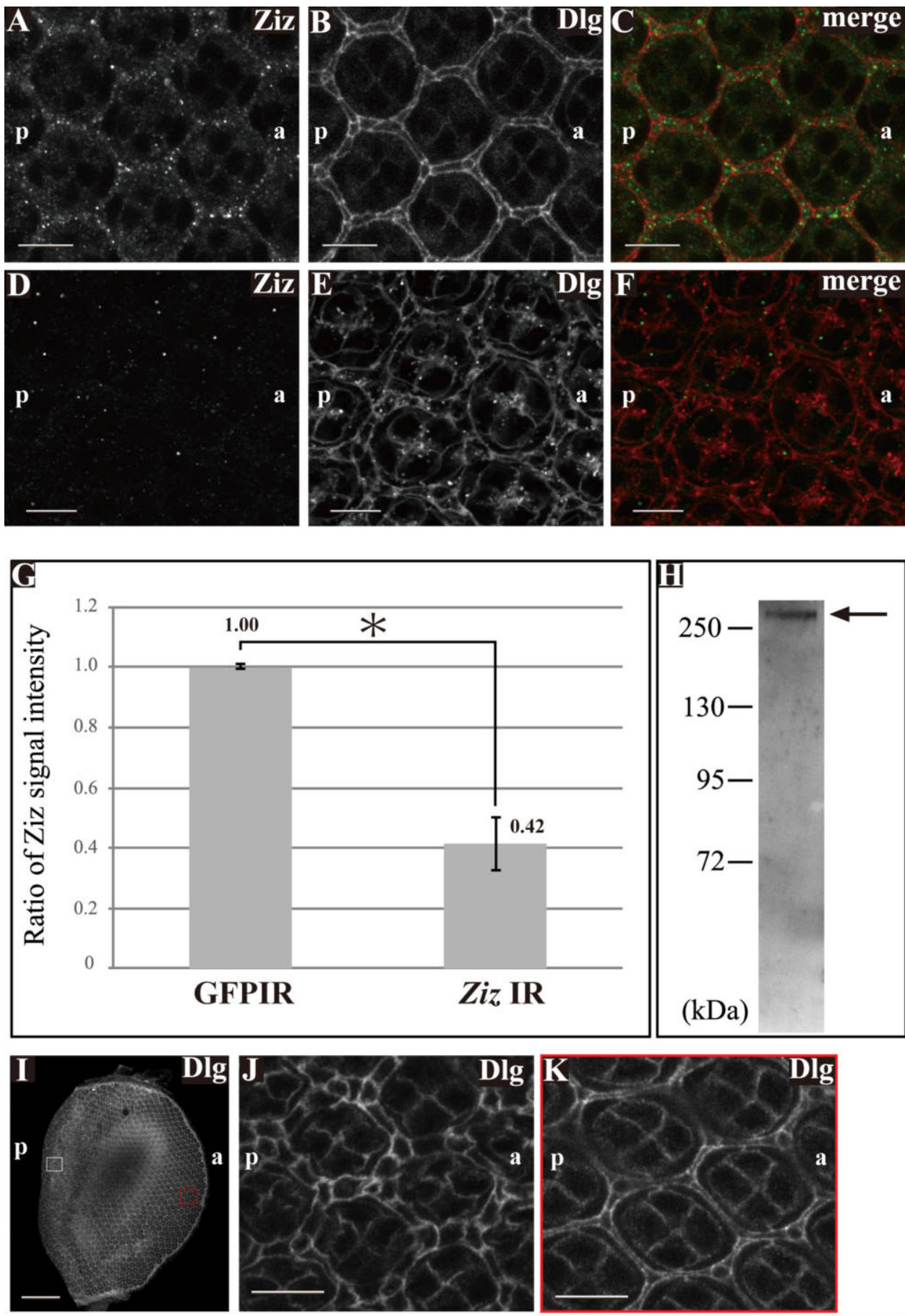

Fig. 4. Ziz-knockdown induced the morphologically aberrant SPCs and TPCs. (A, D) Immnunostaining of 42h APF pupal retina with anti-Ziz IgG. (B, E) Cell membranes were immunostained with anti-Dlg antibody. (C) Merged image of panels A (green) and B (red). (F) Merged image of panels D (green) and E (red). Ziz proteins are localized in SPCs/TPCs and Ziz signals are reduced in the Ziz-knockdown flies. (A-C) GMR-GAL4/Y; +; UAS-GFP IR. (D-F and I-K) GMR-GAL4/Y; UAS-Ziz-IR $6430-6556 /+;+$. (G) Quantification of Ziz signals in the SPCs and TPCs. Ziz signals in the SPCs/TPCs were decreased to $42 \%$ in the Ziz-knockdown flies in compared with the control flies. Error bars represent standard deviations. $p<0.05, \mathrm{n}=3$. (H) Western immunoblot of the extracts from the wild type adult fly heads with anti-Ziz IgG. A single $260 \mathrm{kDa}$ band indicated by arrow was detected. (I) Image of whole pupal retina. (J) Enlarged image of posterior region indicated with white box. (K) Enlarged image of anterior region indicated with red box. The bars indicate $10 \mu \mathrm{m}(\mathrm{A}-\mathrm{F}$ and $\mathrm{J}, \mathrm{K}$ ) or $100 \mu \mathrm{m}(\mathrm{I})$. a, anterior; $\mathrm{p}$, posterior. 

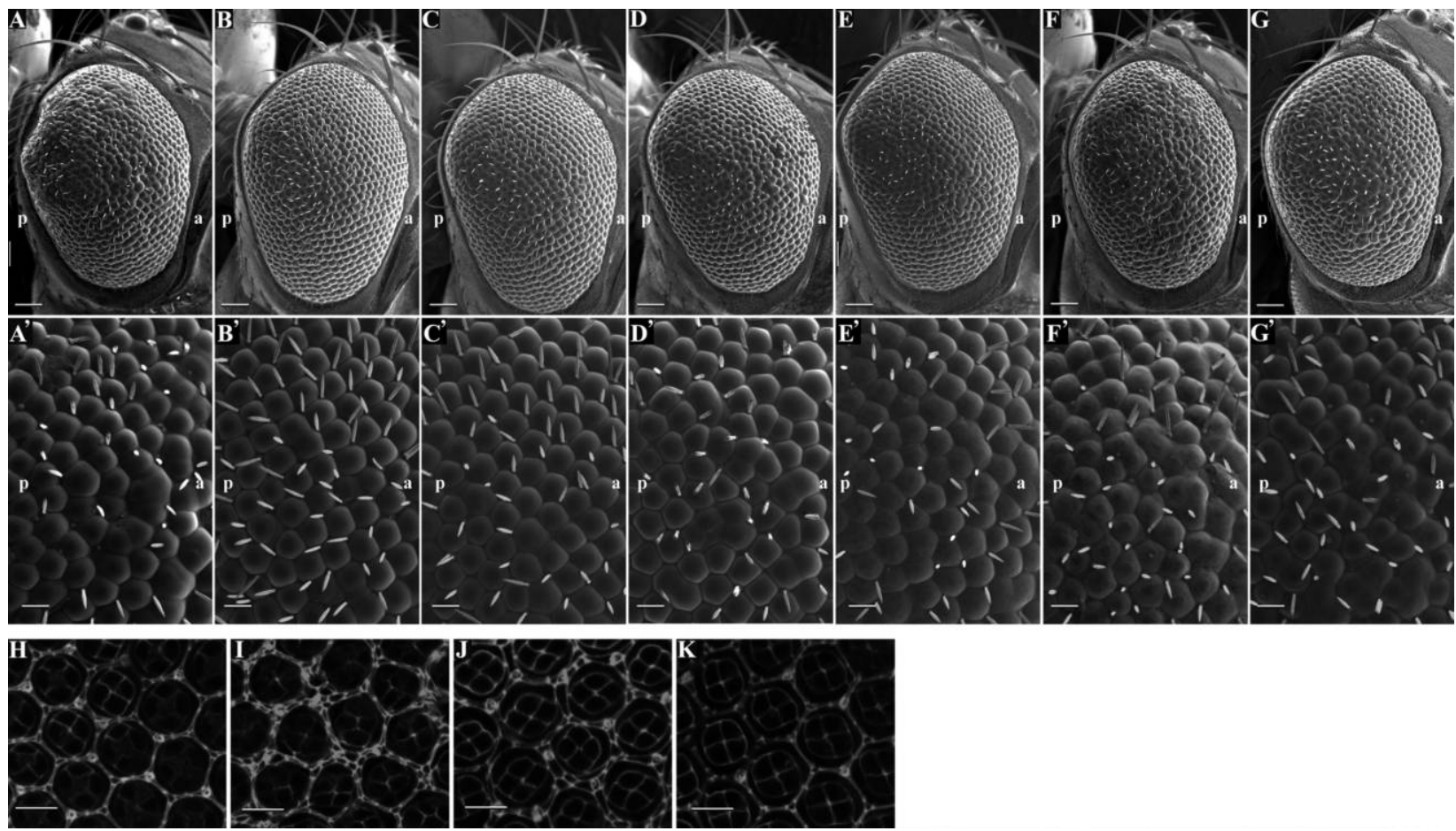

Fig. 5. Genetic interaction between $Z i z$ and genes encoding components of the EGFR signaling pathway. (A-G') Scanning electron micrographs of adult compound eyes. (A, A', I, I') GMR-GAL4/Y; UAS- Ziz-IR $6430-6556 /+$; +. (B, B', J, J') GMR-GAL4/Y; UAS Ziz-IR $6430-6556 /+$; rho $o^{\mathrm{ve}-1 /+}$. (C, C') GMR-GAL4/Y; $U A S-Z i z-I R_{6430-6556} /+; r u^{1 /+}$. (D, D') GMR-GAL4/Y; UAS- Ziz-IR $6430-6556 /+; R a s 85 D^{\mathrm{e2f}} /+$. (E, E', K, K') GMR-GAL4/Y; UAS-Ziz-IR $6430-6556 /+; D l^{3} /+$. (F, F') GMR-GAL4/Y; UAS-Ziz-IR $6430-6556 /+;$ spi $^{1} /+$. (G, G') GMR-GAL4/Y; UAS Ziz-IR $6430-6556 /+;$ egfr 12 /+. (H, H') GMR-GAL4/Y; +; UAS-GFP IR. (H'-K') The arrows indicate orientation of each ommatidium. The flies were developed at $28^{\circ} \mathrm{C}$. The bars indicate $50 \mu \mathrm{m}(\mathrm{A}-\mathrm{G}), 14.2 \mu \mathrm{m}\left(\mathrm{A}^{\prime}-\mathrm{G}^{\prime}\right)$ and $10 \mu \mathrm{m}\left(\mathrm{H}_{-}\right.$ K). a, anterior; p, posterior.

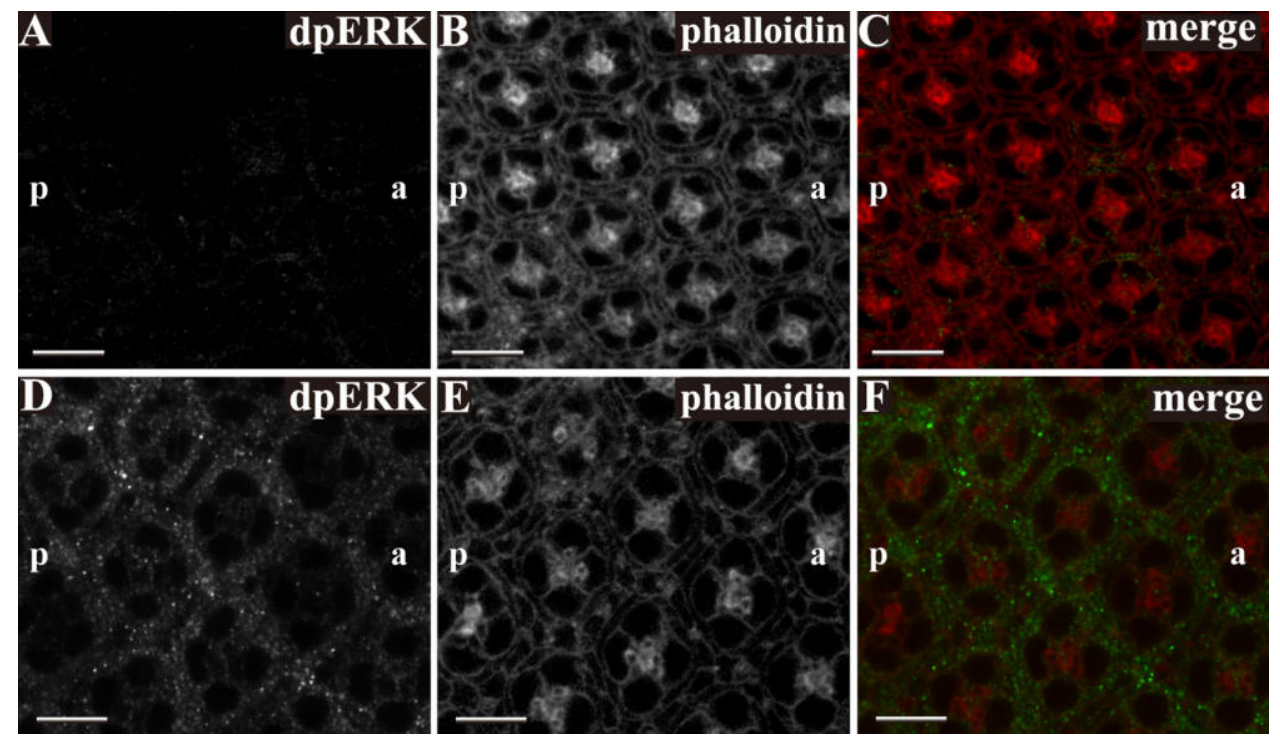

Fig. 6. Ziz-knockdown increased the dpERK signals in the morphologically aberrant SPCs and TPCs. The $42 \mathrm{~h}$ APF pupal retinae were stained with antidpERK IgG and phalloidin. (A-C) GMR-GAL4/Y; UAS-GFPIR/+; +. (D-F) GMR-GAL4/Y; UAS- Ziz-IR $6430-6556 /+$; +. The weak dpERK signals were detected in SPCs and TPCs of control flies (A). In Ziz-knockdown flies, strong signals of dpERK were specially detected in the morphologically aberrant SPCs and TPCs (D). Merged signals of anti-dpERK IgG (green) and phalloidin (red) (C and F). The bars indicate $10 \mu \mathrm{m}$. a, anterior; $\mathrm{p}$, posterior. 


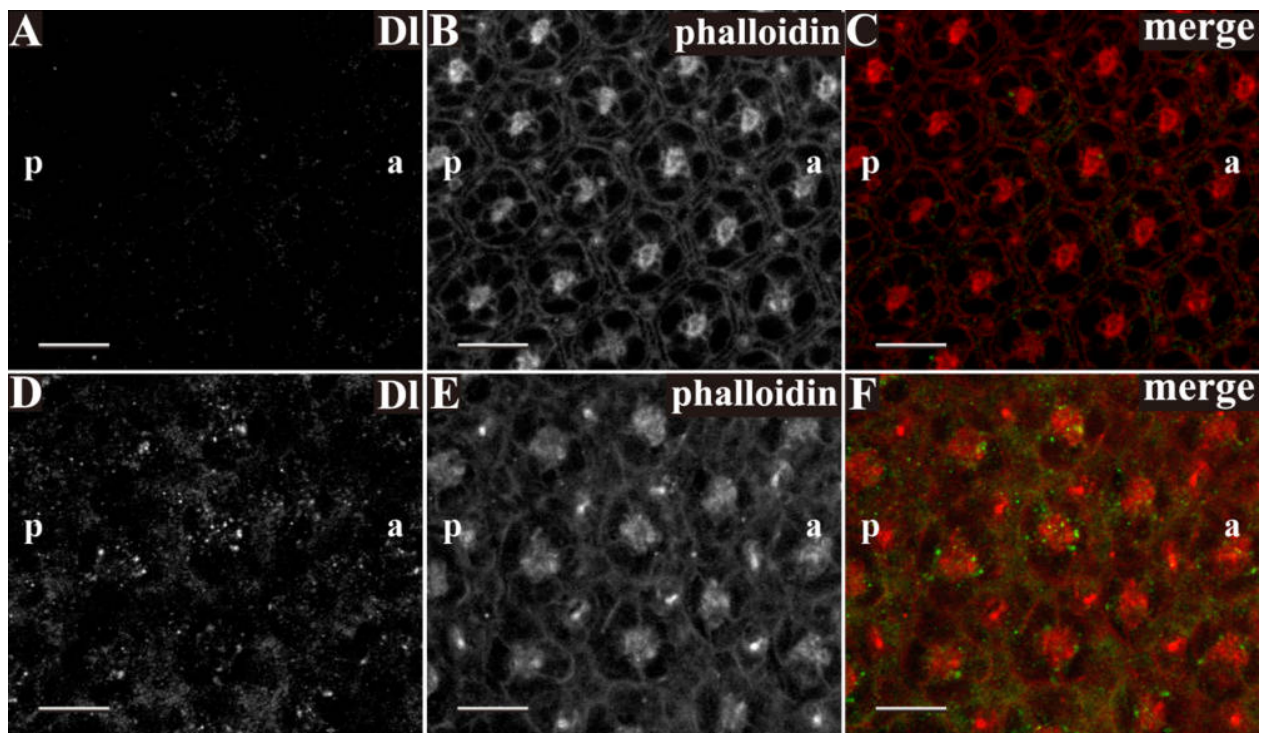

Fig. 7. Ziz-knockdown induced $D l$ expression in the morphologically aberrant SPCs and TPCs. The $42 \mathrm{~h}$ APF pupal retinae were stained with anti-Dl IgG and phalloidin. (A-C) GMR-GAL4/Y; UAS-GFPIR/+; +. (D-F) GMR-GAL4/Y; UAS-Ziz-IR $6430-6556 /+$; +. The weak Dl signals were detected in SPCs and TPCs of control flies (A). In Ziz-knockdown flies, dotted signals of Dl were detected in the morphologically aberrant SPCs and TPCs together with cone cells (D). Merged signals of anti-Dl IgG (green) and phalloidin (red) (C and F). The bars indicate $10 \mu \mathrm{m}$. a, anterior; p, posterior.
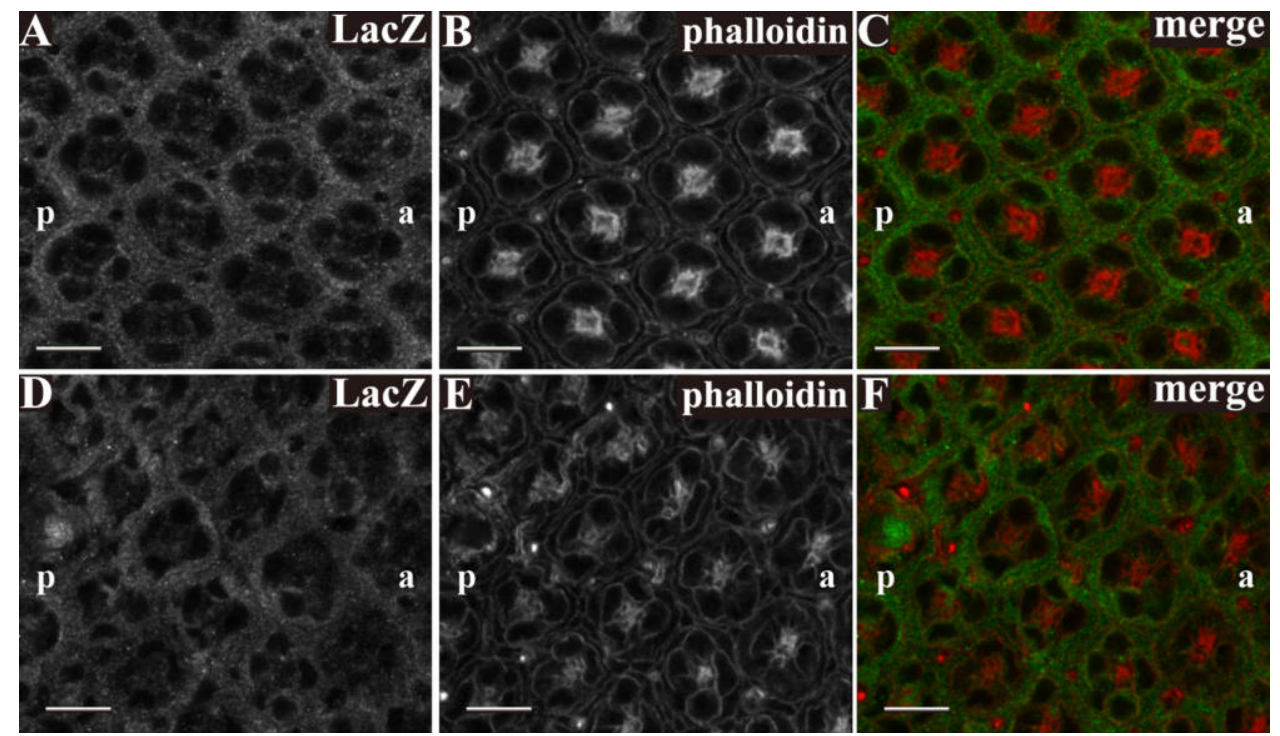

Fig. 8. Ziz-knockdown exerted no effect on Sv-lacZ expression in the morphologically aberrant SPCs and TPCs. The 42hAPF pupal retinae were stained with anti-lacZ IgG and phalloidin. (A-C) GMR-GAL4/Y; UAS-GFP IR/+; Sv-lacZ/+. (D-F) GMR-GAL4/Y; UAS-Ziz-IR $6430-6556 /+$; Sv-lacZ/+. The Sv-lacZ signals were detected in SPCs and TPCs in control flies (A). In Ziz knockdown flies, the Sv-lacZ signals in the morphologically aberrant SPCs and TPCs were not apparently changed (D). Merged signals of anti-lacZ IgG (green) and phalloidin (red) (C and F). The bars indicate $10 \mu \mathrm{m}$. a, anterior; $\mathrm{p}$, posterior.

\section{Genetic interaction between Ziz, and Cdc42}

DOCK family proteins belong to GEF proteins and activate small GTPases including Rho, Rac and Cdc42 (Meller et al., 2005; Côté and Vuori, 2007). It is reported that human Zizimin 1 activates Cdc42 in vitro and in cultured cells
(Meller et al., 2002). We therefore examined genetic interaction between Drosophila Ziz and $c d c 42$. Eye disc specific expression of dominant negative form of $\mathrm{Cdc} 42$ exerted no apparent effect on the adult compound eye morphology (Fig. 9C, $\mathrm{C}^{\prime}$ ) and pigment cells (Fig. 9F). Expression of dominant negative form of $\mathrm{Cdc} 42$ under the background of 

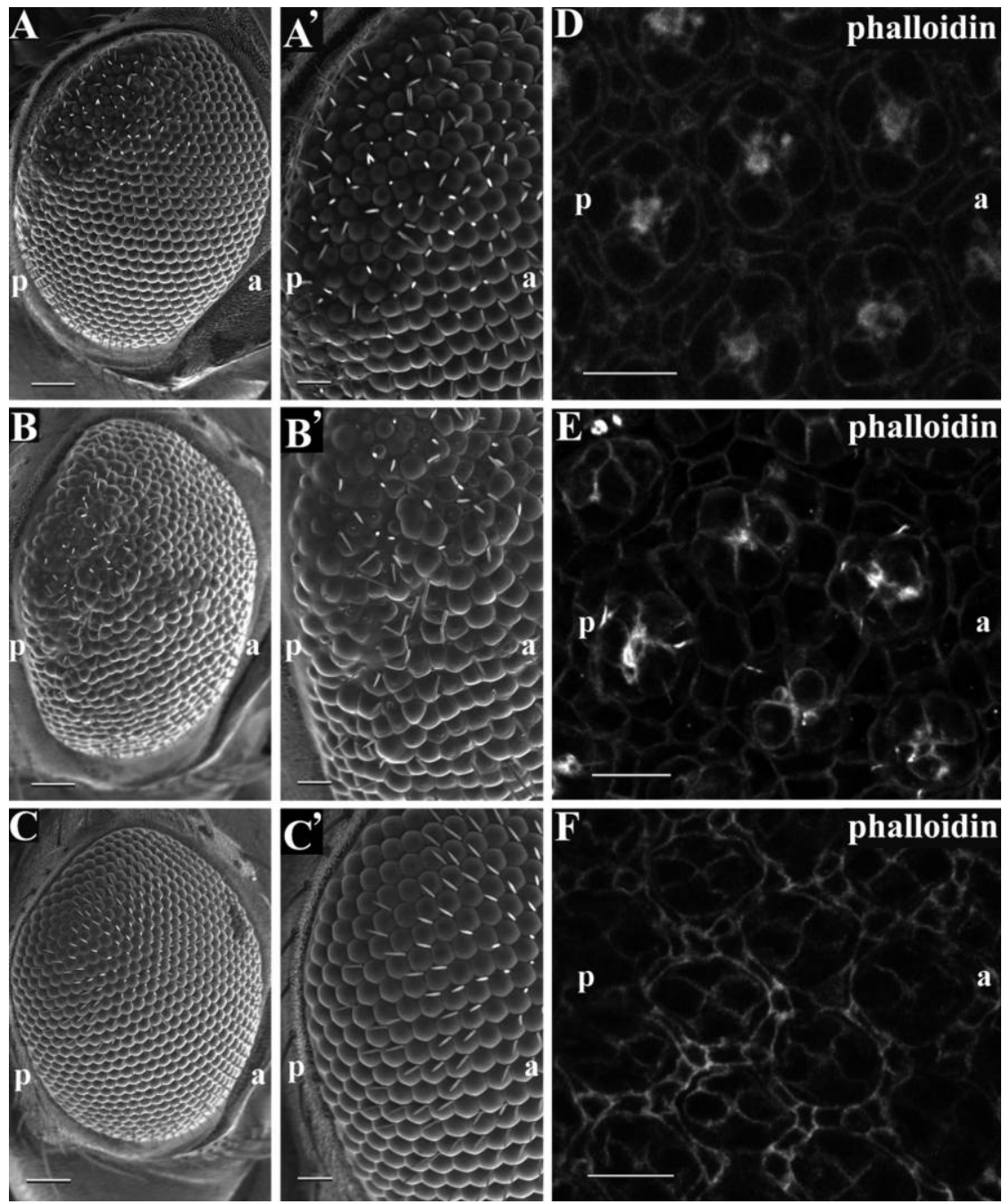

Fig. 9. Genetic interaction between $Z i z$ and $c d c 42$. (A-C) scanning electron micrographs of adult compound eyes. (A', B', $\left.\mathrm{C}^{\prime}\right)$ higher magnification images shown in A, B and C. (D, E, F) The $42 \mathrm{~h}$ APF pupal retinae were stained with phalloidin. (A, A', D) GMR-GAL4/Y; UAS-Ziz-IR $6430-6556 /+$. (B, B', E) GMR-GAL4/Y; UAS-Ziz-IR ${ }_{6430-6556} / P[U A S-C d c 42 . N 17]^{3}$. (C, C', F) GMR-GAL4/Y; +/P[UAS-Cdc42.N17]3. The bars indicate $50 \mu \mathrm{m}(\mathrm{A}-\mathrm{C}), 14.2 \mu \mathrm{m}\left(\mathrm{A}^{\prime}-\right.$ $\left.\mathrm{C}^{\prime}\right)$ and $10 \mu \mathrm{m}(\mathrm{D}-\mathrm{F})$. a, anterior; p, posterior.

Ziz-knockdown enhanced the rough eye phenotype (Fig. 9B, B') and defects in pigment cell differentiation (Fig. 9E) in compared to the Ziz-knockdown alone (Fig. 9A, A' and D). These data suggest the possible cooperation between Ziz and Cdc42 in regulation of pigment cell differentiation.

\section{Ziz is required for proper cell death during development of pupal retinae}

Since it is well known that the survival or cell death of the pigment cells in the eye is highly regulated by EGFR and Notch signaling pathway, Ziz may be involved in proper cell death during development of pupal retinae. We therefore monitored the cell death in Ziz-knockdown flies by immunostaining with anti-active Caspase 3 IgG. In pupal retinae of control flies at $42 \mathrm{~h}$ APF, apoptosis signals were detected (Fig. 10A) and these signals were reduced in $\mathrm{Ziz}$ knockdown flies (Fig. 10D). The quantified data indicate that number of apoptotic cells per ommatidium were decreased by $64 \%$ (Fig. 10G). These results indicate that $\mathrm{Ziz}$ is required for proper cell death during development of pupal retinae.

\section{Discussion}

Although studies in mammalian cultured cells and Dictyostelium revealed the roles of Ziz in cell migration, development, cytokinesis and growth (Pakes et al., 2013), functions of Ziz in specific tissues and organs in multicellular organ- 

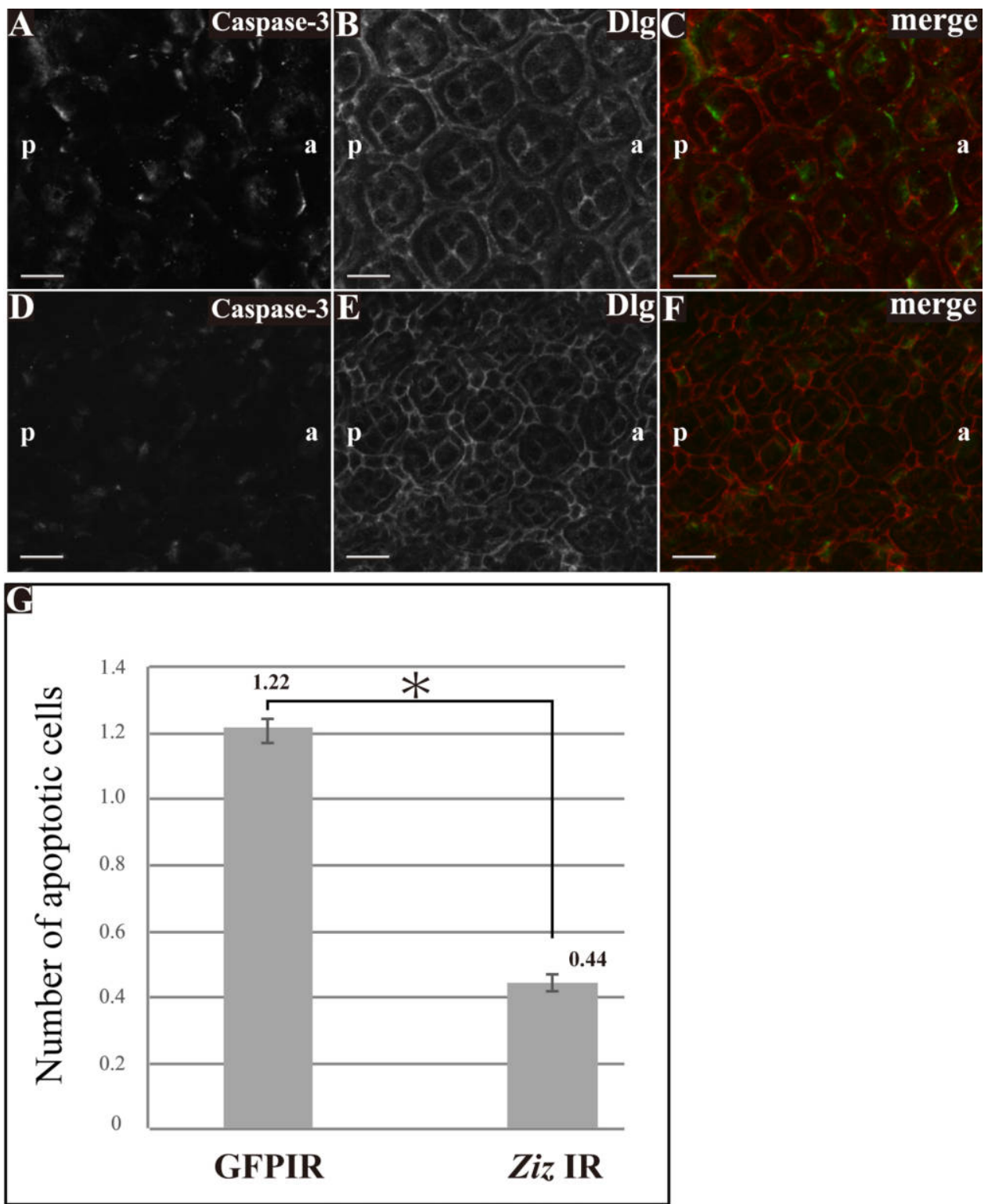

Fig. 10. Ziz-knockdown decreased the active Caspase 3 signals in the pupal retinae. The 42 h APF pupal retinae were stained with anti-active Caspase 3 IgG and anti-Dlg antibody. (A-C) GMR-GAL4/Y; UAS-GFPIR/+; +. (D-F) GMR-GAL4/Y; UAS-Ziz-IR $6430-6556 /+$; +. The active Caspase3 signals were detected in retinae of control flies (A). In Ziz-knockdown flies, the active Caspase3 signals were decreased (D). Merged signals of anti-active Caspase3 IgG (green) and anti-Dlg antibody (red) (C and F). (G) The quantified data of average number of apoptotic cells per each ommatidium. Error bars represent standard deviations. $\mathrm{p}<0.01, \mathrm{n}=200$. The bars indicate $10 \mu \mathrm{m}$. a, anterior; $\mathrm{p}$, posterior.

isms are still not fully understood. In the present study, we revealed that Ziz-knockdown in eye imaginal disc induced the decrease of pigments in adult compound eyes that are associated with increase of SPC- and TPC-like cells with aberrant morphology and orientation in pupal retinae. Zizknockdown may therefore induce defects in proper differentiation of SPC and TPC cells in pupal retinae.

To gain further insight into the mechanism to direct these defects, we examined the $D l$ and $S v$ expression in the pupal retinae. Ziz-knockdown induced expression of Dl in SPCs and TPCs where Ziz is normally highly expressed, but not the expression of $S v$. These observations suggest that $\mathrm{Ziz}$ negatively regulates Dl expression in SPCs and TPCs. Although Dl is a target of EGFR signaling (Tsuda et al., 2002), no genetic interaction was observed between Ziz and some genes for components of the EGFR signaling pathway such as spi or egfr. One possible explanation is that EGFR signal cascade can be amplified progressively and 
therefore only a half reduction of gene dose for spi or egfr may not be sufficient to suppress the effects. In fact, genetic analyses in the present study have revealed that $\mathrm{Ziz}$ genetically interacts with $r h o$ and $r u$ (Fig. 5B, C). Previous studies revealed that $r h o$ and $r u$ cooperate to activate EGFR signaling during Drosophila eye development (Wasserman et al., 2000). Moreover, activation of ERK in SPCs- and TPCs-liken cells was observed in Ziz-knockdown flies. Thus, Ziz very likely negatively regulates EGFR signaling pathway during pigment cell differentiation. Genetic interaction between Drosophila Ziz and $c d c 42$ was observed in the present study, suggesting that $\mathrm{Cdc} 42$ is a likely target of Ziz-GEF activity. Previous studies with mammals revealed that $\mathrm{Cdc} 42$ sustain EGFR signaling by preventing ubiquitin-mediated EGFR degradation (Wu et al., 2003), suggesting the interaction between EGFR signaling and Ziz that is mediated by regulation of $\mathrm{Cdc} 42$.

However, it is also reported that activation of EGFR signaling causes Dl expression in cone cells, and this Dl expression leads to activate Notch-signaling at the pigment cells (Nagaraj and Banerjee, 2007), suggesting the existence of an inhibitory loop between Dl expression and Notch activation. Therefore, we cannot exclude the possibility that $Z i z$-knockdown inhibits Notch activation and leads to Dl expression in the pigments cells. Further studies are needed to clarify this point.

Our previous studies in Drosophila revealed that the DOCK-B protein, Spg positively regulates ERK pathway to control the differentiation of R7 photoreceptor cells and air sac development (Eguchi et al., 2013; Morishita et al., 2017). Spg also activates JNK pathway to promote thorax development (Morishita et al., 2014). In contrast, Zizknockdown exerted no apparent effect in photoreceptor cell differentiation (Fig. 2) and there is no indication for Ziz to be related with the JNK pathway (data not shown). Since EGFR pathway controls Dl activation (Deng et al., 2013), Ziz negatively regulates Dl expression to induce the differentiation of SPCs and TPCs that is mediated by EGFR pathway. Other studies revealed that the DOCK-A protein, Mbc plays a role in myoblast fusion in Drosophila (Erickson et al., 1997; Bour et al., 2000). In any event, Ziz plays a distinct role from those of other DOCK family proteins during Drosophila development.

Acknowledgments. We thank Dr. Y. Hiromi, Bloomington Drosophila Stock Center, Vienna Drosophila Genetic Resource Center and Kyoto Drosophila Genetic Resource Center for fly lines. This study was partially supported by Grants-in-Aid from the Ministry of Education, Science, Sports and Culture of Japan, JST and the JSPS Core-to-Core Program, Asia-Africa Science Platforms, JSPS KAKENHI Grant Number 16K07346.

\section{References}

Biersmith, B., Liu, Z.C., Bauman, K., and Geisbrecht, E.R. 2011. The DOCK protein sponge binds to ELMO and functions in Drosophila embryonic CNS development. PLoS One, 6: e16120.
Bour, B.A., Chakravarti, M., West, J.M., and Abmayr, S.M. 2000. Drosophila SNS, a member of the immunoglobulin superfamily that is essential for myoblast fusion. Genes Dev., 14: 1498-1511.

Brugnera, E., Haney, L., Grimsley, C., Lu, M., Walk, S.F., ToselloTrampont, A.C., Macara, I.G., Madhani, H., Fink, G.R., and Ravichandran, K.S. 2002. Unconventional Rac-GEF activity is mediated through the Dock180-ELMO complex. Nat. Cell Biol., 4: 574-582.

Butler, S.J., Ray, S., and Hiromi, Y. 1997. Klingon, a novel member of the Drosophila immunoglobulin superfamily, is required for the development of the R7 photoreceptor neuron. Development, 124: 781-792.

Carthew, R.W. 2007. Pattern formation in the Drosophila eye. Curr. Opin. Genet. Dev., 17: 309-313.

Chen, Q., Peto, C.A., Shelton, G.D., Mizisin, A., Sawchenko, P.E., and Schubert, D. 2009. Loss of modifier of cell adhesion reveals a pathway leading to axonal degeneration. J. Neurosci., 29: 118-130.

Cimino, P.J., Sokal, I., Leverenz, J., Fukui, Y., and Montine, T.J. 2009. DOCK2 is a microglial specific regulator of central nervous system innate immunity found in normal and Alzheimer's disease brain. Am. J. Pathol., 175: 1622-1630.

Côté, J.F. and Vuori, K. 2007. GEF what? Dock180 and related proteins help Rac to polarize cells in new ways. Trends Cell Biol., 17: 383-393.

deBakker, C.D., Haney, L.B., Kinchen, J.M., Grimsley, C., Lu, M., Klingele, D., Hsu, P.K., Chou, B.K., Cheng, L.C., Blangy, A., Sondek, J., Hengartner, M.O., Wu, Y.C., and Ravichandran, K.S. 2004. Phagocytosis of apoptotic cells is regulated by a UNC-73/TRIO-MIG-2/RhoG signaling module and armadillo repeats of CED-12/ELMO. Curr. Biol., 14: 2208-2216.

Deng, Y., Larrivée, B., Zhuang, Z.W., Atri, D., Moraes, F., Prahst, C., Eichmann, A., and Simons, M. 2013. Endothelial RAF1/ERK activation regulates arterial morphogenesis. Blood, 121: 3988-3896.

Detera-Wadleigh, S.D., Liu, C.Y., Maheshwari, M., Cardona, I., Corona, W., Akula, N., Steele, C.J., Badner, J.A., Kundu, M., Kassem, L., Potash, J.B., Gibbs, R., Gershon, E.S., and McMahon, F.J. (NIMH Genetics Initiative for Bipolar Disorder Consortium.) 2007. Sequence variation in DOCK9 and heterogeneity in bipolar disorder. Psychiatr. Genet., 17: 274-286.

Dumontier, M., Höcht, P., Mintert, U., and Faix, J. 2000. Rac1 GTPases control filopodia formation, cell motility, endocytosis, cytokinesis and development in Dictyostelium. J. Cell Sci., 113: 2253-2265.

Eguchi, K., Yoshioka, Y., Yoshida, H., Morishita, K., Miyata, S., Hiai, H., and Yamaguchi, M. 2013. The Drosophila DOCK family protein sponge is involved in differentiation of R7 photoreceptor cells. Exp. Cell Res., 319: 2179-2195.

Engelhardt, K.R., McGhee, S., Winkler, S., Sassi, A., Woellner, C., LopezHerrera, G., Chen, A., Kim, H. S., Lloret, M.G., Schulze, I., Ehl, S., Thiel, J., Pfeifer, D., Veelken, H., Niehues, T., Siepermann, K., Weinspach, S., Reisli, I., Keles, S., Genel, F., Kutukculer, N., Camcioğlu, Y., Somer, A., Karakoc-Aydiner, E., Barlan, I., Gennery, A., Metin, A., Degerliyurt, A., Pietrogrande, M.C., Yeganeh, M., Baz, Z., Al-Tamemi, S., Klein, C., Puck, J.M., Holland, S.M., McCabe, E.R., Grimbacher, B., and Chatila, T.A. 2009. Large deletions and point mutations involving the dedicator of cytokinesis 8 (DOCK8) in the autosomal-recessive form of hyper-IgE syndrome. J. Allergy Clin. Immunol., 124: 1289-1302.

Erickson, M.R., Galletta, B.J., and Abmayr, S.M. 1997. Drosophila myoblast city encodes a conserved protein that is essential for myoblast fusion, dorsal closure, and cytoskeletal organization. J. Cell Biol., 138: 589-603.

Gadea, G., Sanz-Moreno, V., Self, A., Godi, A., and Marshall, C.J. 2008. DOCK10-mediated Cdc42 activation is necessary for amoeboid invasion of melanoma cells. Curr. Biol., 18: 1456-1465.

Harada, Y., Tanaka, Y., Terasawa, M., Pieczyk, M., Habiro, K., Katakai, T., Hanawa-Suetsugu, K., Kukimoto-Niino, M., Nishizaki, T., Shirouzu, 
M., Duan, X., Uruno, T., Nishikimi, A., Sanematsu, F., Yokoyama, S., Stein, J.V., Kinashi, T., and Fukui, Y. 2012. DOCK8 is a Cdc42 activator critical for interstitial dendritic cell migration during immune responses. Blood, 119: 4451-4461.

Jaffe, A.B. and Hall, A. 2005. Rho GTPases: biochemistry and biology. Annu. Rev. Cell Dev. Biol., 21: 247-269.

Kim, J.Y., Oh, M.H., Bernard, L.P., Macara, I.G., and Zhang, H. 2011. The RhoG/ELMO1/Dock180 signaling module is required for spine morphogenesis in hippocampal neurons. J. Biol. Chem., 286: 3761537624.

Kölsch, V., Charest, P.G., and Firtel, R.A. 2008. The regulation of cell motility and chemotaxis by phospholipid signaling. J. Cell Sci., 121: $551-559$.

Kramer, S., West, S.R., and Hiromi, Y. 1995. Cell fate control in the Drosophila retina by the orphan receptor seven-up: its role in the decisions mediated by the ras signaling pathway. Development, 121: 1361-1372.

Kuramoto, K., Negishi, M., and Katoh, H. 2009. Regulation of dendrite growth by the Cdc42 activator Zizimin1/Dock9 in hippocampal neurons. J. Neurosci. Res., 87: 1794-1805.

Laurin, M., Fradet, N., Blangy, A., Hall, A., Vuori, K., and Côté, J.F. 2008. The atypical Rac activator Dock180 (Dock1) regulates myoblast fusion in vivo. Proc. Natl. Acad. Sci. USA, 105: 15446-15451.

Malartre, M. 2016. Regulatory mechanisms of EGFR signaling during Drosophila eye development. Cell. Mol. Life Sci., 73: 1825-1843.

Meller, N., Irani-Tehrani, M., Kiosses, W.B., Del Pozo, M.A., and Schwartz, M.A. 2002. Zizimin1, a novel Cdc42 activator, reveals a new GEF domain for Rho proteins. Nat. Cell Biol., 4: 639-647.

Meller, N., Merlot, S., and Guda, C. 2005. CZH proteins: a new family of Rho-GEFs. J. Cell Sci., 118: 4937-4946.

Miyamoto, Y., Yamauchi, J., Sanbe, A., and Tanoue, A. 2007. Dock6, a Dock-C subfamily guanine nucleotide exchanger, has the dual specificity for Rac1 and Cdc42 and regulates neurite outgrowth. Exp. Cell Res., 313: 791-804.

Miyamoto, Y. and Yamauchi, J. 2010. Cellular signaling of Dock family proteins in neural function. Cell. Signal., 22: 175-182.

Mlodzik, M., Hiromi, Y., Weber, U., Goodman, C.S., and Rubin, G.M. 1990. The Drosophila seven-up gene, a member of the steroid receptor gene superfamily, controls photoreceptor cell fates. Cell, 60: 211-224.

Mondal, S., Neelamegan, D., Rivero, F., and Noegel, A.A. 2007. GxcDD, a putative RacGEF, is involved in Dictyostelium development. BMC Cell Biol., 8: 23.

Morishita, K., Ozasa, F., Eguchi, K., Yoshioka, Y., Yoshida, H., Hiai, H., and Yamaguchi, M. 2014. Drosophila DOCK family protein sponge regulates the JNK pathway during thorax development. Cell Struct. Funct., 39: 113-124.

Morishita, K., Suong, D.N.A., Yoshida, H., and Yamaguchi, M. 2017. The Drosophila DOCK family protein Sponge is required for development of the air sac primordium. Exp. Cell Res., 354: 95-102.

Nagaraj, R. and Banerjee, U. 2007. Combinatorial signaling in the specification of primary pigment cells in the Drosophila eye. Development, 134: 825-831.

Namekata, K., Enokido, Y., Iwasawa, K., and Kimura, H. 2004. MOCA induces membrane spreading by activating Rac1. J. Biol. Chem., 279: 14331-14337.

Pakes, N.K., Veltman, D.M., and Williams, R.S.B. 2013. Zizimin and Dock guanine nucleotide exchange factors in cell function and disease. Small GTPases, 4: 22-27.
Pankratz, N., Dumitriu, A., Hetrick, K.N., Sun, M., Latourelle, J.C., Wilk, J.B., Halter, C., Doheny, K.F., Gusella, J.F., Nichols, W.C., Myers, R.H., Foroud, T., and DeStefano, A.L. 2011. Copy number variation in familial Parkinson disease. PLoS One, 6: e20988.

Para, A., Krischke, M., Merlot, S., Shen, Z., Oberholzer, M., Lee, S., Briggs, S., and Firtel, R.A. 2009. Dictyostelium Dock180-related RacGEFs regulate the actin cytoskeleton during cell motility. Mol. Biol. Cell, 20: 699-707.

Pertz, O.C., Wang, Y., Yang, F., Wang, W., Gay, L.J., Gristenko, M.A., Clauss, T.R., Anderson, D.J., Liu, T., Auberry, K.J., Camp, D.G. 2nd, Smith, R.D., and Klemke, R.L. 2008. Spatial mapping of the neurite and soma proteomes reveals a functional $\mathrm{Cdc} 42 / \mathrm{Rac}$ regulatory network. Proc. Natl. Acad. Sci. USA, 105: 1931-1936.

Reif, K. and Cyster, J. 2002. The CDM protein DOCK2 in lymphocyte migration. Trends Cell Biol., 12: 368-373.

Roignant, J.Y. and Treisman, J.E. 2009. Pattern formation in the Drosophila eye disc. Int. J. Dev. Biol., 53: 795-804.

Sakabe, I., Asai, A., Iijima, J., and Maruyama, M. 2012. Age-related guanine nucleotide exchange factor, mouse Zizimin2, induces filopodia in bone marrow-derived dendritic cells. Immun. Ageing, 9: 2 .

Sampson, C.J., Valanne, S., Fauvarque, M.O., Hultmark, D., Rämet, M., and Williams, M.J. 2012. The RhoGEF Zizimin-related acts in the Drosophila cellular immune response via the Rho GTPases Rac2 and Cdc42. Dev. Comp. Immunol., 38: 160-168.

Tachi, N., Hashimoto, Y., and Matsuoka, M. 2012. MOCA is an integrator of the neuronal death signals that are activated by familial Alzheimer's disease-related mutants of amyloid $\beta$ precursor protein and presenilins. Biochem. J., 442: 413-422.

Tsuda, L., Nagaraj, R., Zipursky, S.L., and Banerjee, U. 2002. An EGFR/Ebi/Sno pathway promotes delta expression by inactivating $\mathrm{Su}(\mathrm{H}) / \mathrm{SMRTER}$ repression during inductive notch signaling. Cell, 110: 625-637.

Vasyutina, E., Martarelli, B., Brakebusch, C., Wende, H., and Birchmeier, C. 2009. The small G-proteins Rac1 and Cdc42 are essential for myoblast fusion in the mouse. Proc. Natl. Acad. Sci. USA, 106: 8935-8940.

Wasserman, J.D., Urban, S., and Freeman, M. 2000. A family of rhomboid-like genes: Drosophila rhomboid-1 and roughoid/rhomboid-3 cooperate to activate EGF receptor signaling. Genes Dev., 14: 16511663.

Watabe-Uchida, M., John, K.A., Janas, J.A., Newey, S.E., and Van Aelst, L. 2006. The Rac activator DOCK7 regulates neuronal polarity through local phosphorylation of stathmin/Op18. Neuron, 51: 727-739.

Wolff, T. and Ready, D.F. 1993. Pattern formation in the Drosophila retina. In The Development of Drosophila menlanogaster, II: 1277-1325.

Wu, W.J., Tu, S., and Cerione, R.A. 2003. Activated Cdc42 sequesters c$\mathrm{Cbl}$ and prevents EGF receptor degradation. Cell, 114: 715-725.

Yajnik, V., Paulding, C., Sordella, R., McClatchey, A.I., Saito, M., Wahrer, D.C., Reynolds, P., Bell, D.W., Lake, R., van den Heuvel, S., Settleman, J., and Haber, D.A. 2003. DOCK4, a GTPase activator, is disrupted during tumorigenesis. Cell, 112: 673-684.

Zheng, Y., Zangrilli, D., Cerione, R.A., and Eva, A. 1996. The pleckstrin homology domain mediates transformation by oncogenic dbl through specific intracellular targeting. J. Biol. Chem., 271: 19017-19020.

(Received for publication, May 17, 2017, accepted, June 29, 2017 and published online, July 13, 2017) 